\title{
Correction to: A small-molecule/cytokine combination enhances hematopoietic stem cell proliferation via inhibition of cell differentiation
}

\author{
Lan Wang ${ }^{1}$, Xin Guan ${ }^{1}$, Huihui Wang ${ }^{2}$, Bin Shen ${ }^{1}$, Yu Zhang ${ }^{1}$, Zhihua Ren ${ }^{1,2}$, Yupo Ma ${ }^{1,3}$, Xinxin Ding ${ }^{1,4}$ and \\ Yongping Jiang ${ }^{1,2^{*}}$
}

\section{Correction to: Stem Cell Research \& Therapy (2017) 8:169 https://doi.org/10.1186/s13287-017-0625-z}

Following the publication of the original article [1], the authors identified an error in Fig. 4b. The authors noticed that the gel bands of Runx1 were accidentally used again as the ones of Bmi1 during the layout of figures. It has been corrected after they double checked the original data. The results and conclusion concluded in this paper are still valid. 


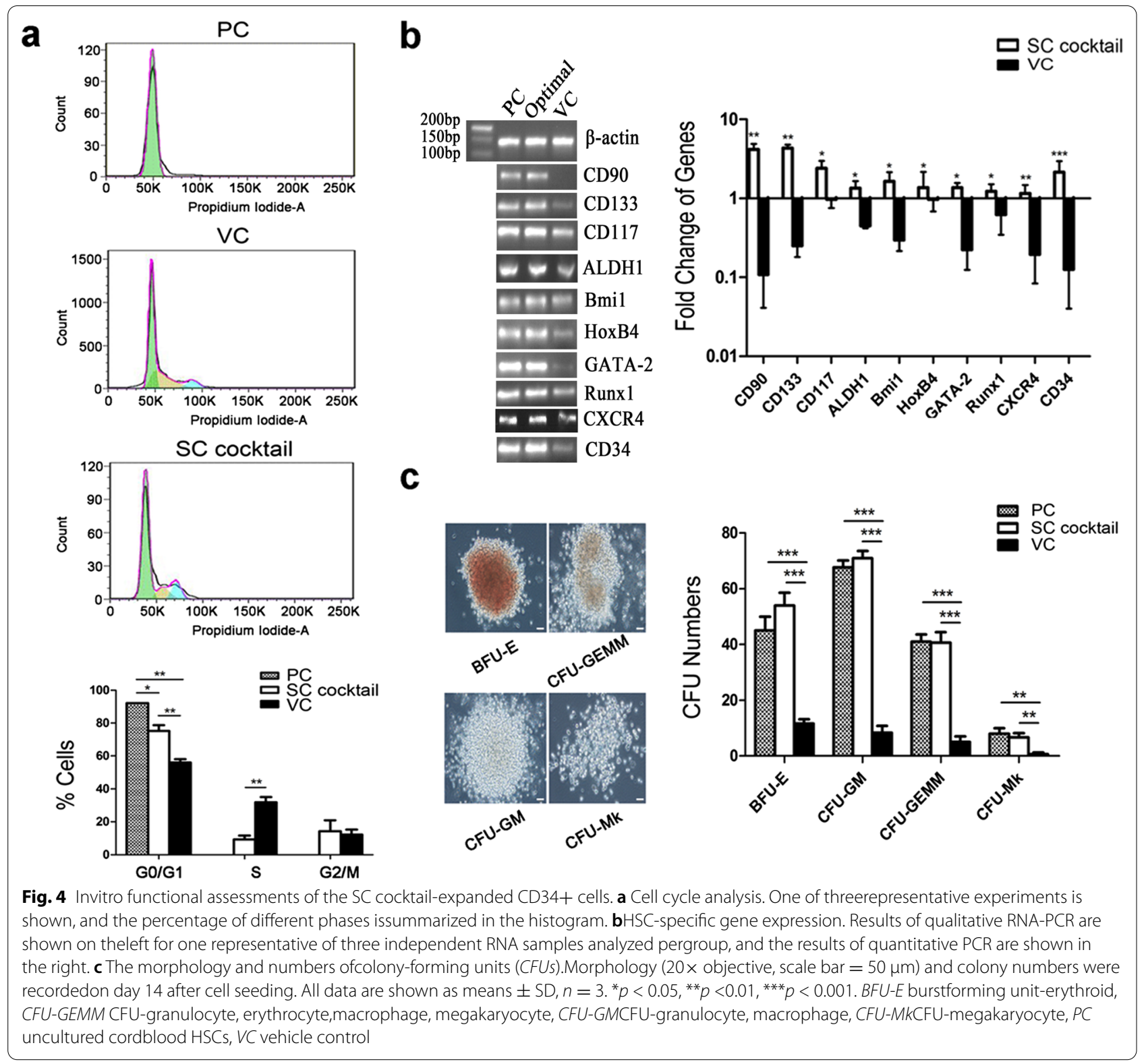

\section{Author details}

'Biopharmaceutical R\&D Center, Chinese Academy of Medical Sciences \& Peking Union Medical College, Suzhou, China. 'Biopharmagen Corp, Suzhou, China. ${ }^{3}$ Department of Pathology, The State University of New York at Stony Brook, Stony Brook, NY, USA. ${ }^{4}$ College of Nanoscale Science and Engineering, SUNY Polytechnic Institute, Albany, NY, USA.

Published online: 17 August 2021

\section{Reference}

1. Wang $L$, et al. A small-molecule/cytokine combination enhances hematopoietic stem cell proliferation via inhibition of cell differentiation. Stem Cell Res Ther. 2017;8:169. https://doi.org/10.1186/s13287-017-0625-z.

\section{Publisher's Note}

Springer Nature remains neutral with regard to jurisdictional claims in published maps and institutional affiliations. 